\title{
Pengaruh Relationship Marketing Terhadap Customer Retention pada Studio Musik 58 Surakarta
}

\author{
Indah Handaruwati, Obed Christian Wibowo \\ Fakultas Ekonomi Universitas Kristen Surakarta \\ Jln.R.Wolter Monginsidi 36-38 Surakarta \\ indahhandaruwati80@gmail.com
}

\begin{abstract}
This study aims to analyze the effect of Relationship Marketing on Customer Retention in 58 Surakarta music studios. In connection with this problem, the following hypothesis is proposed, H1: Allegedly there is the influence of Customer Experience on Customer Retention, H2: Allegedly there is an influence of Communication on Customer Retention, H3: Allegedly there is the influence of Conflict Handling on Customer Retention, H4: Allegedly there is the influence of Customer Experience, Communication, Conflict Handling simultaneously for Customer Retention. The population in this study were all customers of Surakarta 58 studio music studio rental services, sampling using purposive sampling and convenience sampling techniques. The samples used in this study were 80 consumers. Data collection using a questionnaire. Data analysis was performed with multiple linear regression analysis test with SPSS 16.00 software. The results showed that Customer Experience had no significant effect on Customer Retention with a significance value of 0.142, Communication had a significant effect on Customer Retention with a significance value of 0.045, Conflict Handling had a significant effect on Customer Retention with a significant value of 0,000, Customer Experience, Communication and Conflict Handling had a significant effect Simultaneous to Customer Retention of 27,691.
\end{abstract}

Keywords- Relationship Marketing, Customer Experience, Communication, Conflict Handling, Customer Retention.

\begin{abstract}
Abstrak- Penelitian ini bertujuan untuk menganalisis pengaruh Relationship Marketing terhadap Customer Retention pada studio musik 58 Surakarta. Sehubungan dengan masalah tersebut, diajukan hipotesis sebagai berikut, H1 : Diduga ada pengaruh Customer Experience terhadap Customer Retention, H2: Diduga ada pengaruh Communication terhadap Customer Retention, H3: Diduga ada pengaruh Conflict Handling terhadap Customer Retention, H4: Diduga ada pengaruh Customer Experience, Communication, Conflict Handling secara simultan terhadap Customer Retention. Populasi dalam penelitian ini adalah semua pelanggan pengguna jasa sewa studio musik 58 Surakarta, pengambilan sampel menggunakan teknik purposive sampling dan convenience sampling.Sampel yang digunakan dalam penelitian ini sebanyak 80 responden.Pengumpulan data menggunakan kuesioner.Analisis data dilakukan dengan uji analisis regresi linear berganda dengan software SPSS 16.00. Hasil penelitian menunjukan bahwa Customer Experience tidak berpengaruh secara signifikan terhadap Customer Retention dengan nilai signifikansi 0.142, Communication berpengaruh signifikan terhadap Customer Retention dengan nilai signifikansi 0.045, Conflict Handling berpengaruh signifikan terhadap Customer Retention dengan nilai signifikan 0.000, Customer Experience, Communication dan Conflict Handling berpengaruh secara simultan terhadap Customer Retention sebesar 27.691.
\end{abstract}

Kata Kunci- Relationship Marketing, Customer Experience, Communication, Conflict Handling, Customer Retention.

\section{PENDAHULUAN}

Perkembangan industri musik Indonesia saat ini, khususnya dilihat dari komunitas anak muda mengalami kemajuan yang pesat. Banyak anak muda yang memiliki hobi bermain musik dan mengembangkan bakatnya dengan cara mendirikan sebuah band, mulai dari yang sekedar hobi maupun yang serius untuk berkarier dalam bidang musik. Mereka tentulah membutuhkan tempat untuk berlatih dengan kata lain mereka membutuhkan sebuah studio untuk melatih bakat dan kekompakan bermusik. Dengan pangsa pasar yang besar tersebut maka usaha studio musik ini pun secara otomatis menjadi banyak pelakunya, tentunya berujung kepada tingkat persaingan yang semakin ketat. Apalagi di kota besar, bisnis seperti ini memerlukan strategi tersendiri agar bisa bertahan. Hingga sekarang bisnis ini masih bisa diandalkan untuk meraup keuntungan besar, seiring dengan semakin moderennya gaya hidup anak muda sebagai pangsa pasar terbesar bisnis studio musik. Bahkan trennya tidak terbatas populer dikota-kota besar namun, jumlah band didaerah pun semakin meningkat.Apalagi ditambah dengan semakin menjanjikannya profesi seorang pemusik dan pemain band sekarang ini, membuat banyak pelaku usaha melirik bisnis jasa sewa studio musik. Fenomena ini mengakibatkan persaingan dalam mempertahankan pelanggan.

Relationship marketing adalah strategi bisnis dan pemasaran yang mempergunakan kekuatan keinginan pelanggan. Relationship marketing merupakan orientasi strategi yang memfokuskan pada mempertahankan dan mengembangkan pelanggan yang ada, lebih dari pada menarik pelanggan baru (Zeithml dan Bitner, 2013 : 138). Tahir (2005) dalam Nikmah (2017) menentukan sembilan dimensi yang sangat penting un- 
tuk membuat pemasaran hubungan berhasil yaitu kepercayaan, komitmen, ikatan sosial, empati, pengalaman, memenuhi janji pelanggan, kepuasan, hubungan internal pemasaran dan komunikasi. Sedangkan Ndubisi dan Wah (2005) dalam Nikmah (2017) menjelaskan Relationship marketing memiliki dimensi kepercayaan, komitmen, komunikasi, penanganan konflik dan kompetensi. Oleh sebab itu penelitian ini mengambil tiga variabel Relationship markeing yaitu costumer experience, communicationdan conflict handling. Alasaan memilih 3 variabel ini karena ketika peneliti berlatih di studio ini terdapat kesalahan pada penempatan waktu, ketika terjadi kesalahan itu terlihat bahwa pemilik studio menangani masalah itu dengan baik, dengan cara mengkomunikasikan permasalahan ini kepada kedua belah pihak dan pemilik studio mau bertanggung jawab dengan kesalahannya dengan cara mengganti waktu latihan dengan ruang studio lain yang kosong pada waktu selanjutnya. Komunikasi yang baik dalam menangani konflik dengan konsumen atau pelanggan akan memberikan pengalaman yang berkesan baik sehingga konsumen atau pelanggan yang terlibat menjadi semakin percaya pada lembaga ini.

Peningkatan hubungan dengan pelanggan menjadi salah satu faktor penting untuk tetap mempertahankan pelanggan.Hubungan yang dibina tidak hanya sekedar hubungan jangka pendek, melainkan hubungan jangka panjang.Untuk mewujudkan hal tersebut perusahaan tidak hanya berorientasi pada transaksi penjualannya saja, melainkan menjalin hubungan jangka panjang antara konsumen dan pelanggan. Maka pendekatan relationship marketing perlu diterapkan dalam perusahaan. Karena berorientasi pada hubungan jangka panjang, fokus dari kegiatan relationship marketing bukan sekedar mendapatkan pelanggan sebanyak-banyaknya, melainkan lebih memprioritaskan pada mempertahankan pelanggan yang sudah ada dengan sebaik-baiknya. Rahmiati (2016) menjelaskan inti dari Relationship marketing adalah meretensi atau mempertahankan pelanggan dengan cara membangun hubungan timbal balik yang saling menguntungkan antara perusahaan dengan pihakpihak yang terkait dengan operasionalnya. Salah satu tujuan dari penggunaan program relationship marketing adalah fokus pada customer retention.

Zangmo et al (2015) menyatakan bahwa customer retention adalah bagaimana meningkatkan penjualan dengan memuaskan dan melayani konsumen, agar mereka terus kembali. Menurut Singh dan Khan (2012) costumer retention adalah aktifitas organisasi penjualan dalam melakukan upaya untuk mengurangi customer yang gagal dipertahankan. Retensi pelanggan dimulai sejak perusahaan pertama kali melakukan kontak dengan pelanggan hingga perusahaan bisa menjalin hubungan jangka panjang dengan pelanggan.Menurut sebuah survey dalam industri tertentu, peningkatan $5 \%$ dalam retensi pelanggan, akan dapat meningkatkan profitabilitas sebesar $25 \%$ hingga $85 \%$ dalam hal net present value. Sebaliknya jika pelanggan kecewa, tidak puas mereka cenderung untuk pergike perusahaan yang lain, hal ini menyebabkan revenue perusahaan menurun dan biaya per customer meningkat serta laba akan semakin tergerus, itulah sebabnya saat ini banyak perusahaan yang sudah menyadari betapa pentingnya mempertahankan pelanggan setia

Studio Musik 58 adalah salah satu studio musik yang berada di daerah Sumber Surakarta. Studio musik ini bergerak di bidang jasa persewaan ruang atau tempat latihan yang dilengkapi dengan berbagai jenis alat musik.Pelanggan jasa sewa Studio Musik 58 adalah kalangan pelajar yang tergabung dalam band-band pelajar dan kalangan umum yang tergabung dalam band-band indie. Fasilitas yang dimiliki di studio ini adalah alat musik standar lengkap drum, gitar, bass, keyboard beserta ampli dan mixer, untuk ruangan dilengkapi dengan AC dan satu buah tv LED ditambah dengan akses internet.

Di Surakarta sendiri ada 8 studio musik yang menjadi tempat latihan anak band yaitu Rams studio, Karmisa Studio, Hello Studio, Dream Studio, 87 Studio, RDT Studio, Blue Studio. Masing-masing pemilik studio musik memiliki strategi tersendiri guna menarik pelanggan baru maupun mempertahankan pelanggan lama.Agar dapat bertahan dalam menghadapi persaingan yang semakin kompetitif, pemilik studio musik harus selalu berorientasi pada pelanggan dengan melibatkan seluruh bagian yang ada di dalam perusahaan. Salah satu cara yang dapat ditempuh pemilik studio dalam memenangkan persaingan tersebut adalah membangun hubungan jangka panjang dengan pelanggan melalui penerapan konsep relationship marketing.

\section{Relationship Marketing}

\section{KAJIAN PUSTAKA}

Sivesan (2012) mengatakan bahwa relationship marketing adalah konsep yang sangat penting untuk menarik dan mempertahankan pelanggan dalam sebuah organisasi. Dalam dunia bisnis moderen, fokus pemasaran mencerminkan pergerakan perubahan dari pemasaran transaksional ke relationship marketing. Membangun, memelihara, dan selalu meningkatkan hubungan pelanggan merupakan aspek penting dari 
bisnis. Konsep relationship marketing secara luas dipahami, baik itu secara akademis dan professional dimana tujuannya adalah untuk meningkatkan hubunganyang kuat dan menjadikan pelanggan yang acuh tak acuh menjadi loyal. Velnampy dan Sivesan (2012) mengatakan bahwa relationship marketing merupakan salah satu strategi pemasaran kontenporer untuk semua perusahaan demi memenuhi kebutuhan dan keinginan pelamggan. Dilihat dari sudut pandang pelanggan, faktor-faktor penting yang digunakan untuk memenuhi kebutuhan para pelanggan adalah adanya komitmen, kepercayaan, mutualis, dan hubungan jangka panjang dengan pelanggan. Relationship marketing menurut Saputra dan Ariningsih (2014) merupakan sebuah konsep strategi pemasaran yang berupaya menjalin hubungan jangka panjang dengan para pelanggan, yaitu mempertahankan hubungan yang kokoh dan saling menguntungkan antara penyedia jasa dan pelanggan yang dapat membangun transaksi ulangan dan menciptakan loyalitas pelanggan.

\section{Customer Experience}

Membangun pengalaman pelanggan (customer experience) menjadi bagian penting dalam strategi pemasaran karena pengalaman adalah tahapan utama untuk merebut hati pelanggan. Menurut Chen dan Lin (2014) customer experience adalah sebagai pengakuan kognitif atau persepsi menstimulasi motivasi pelanggan. Pengakuan atau persepsi tersebut dapat meningkatkan nilai produk dan jasa. Customer Experience merupakan hasil interaksi konsumen dengan perusahaan secara fisik dan emosional [1]. Hasil interaksi ini dapat membekas dibenak konsumen dan mempengaruhi penilaian konsumen terhadap perusahaan.Salim dkk (2013) menjelaskan bahwa customer experience dapat diukur dengan menggunakan lima faktor utama yaitu :

a. Sensory Experience. Sensory Experience didefinisikan sebagai usaha penciptaan pengalaman yang berkaitan dengan panca indera melalui penglihatan, suara, sentuhan, rasa, dan bau. Di mana digunakan untuk mendiferensiasikan perusahaan dan produknya di market, memotivasi konsumen untuk mau membeli produk tersebut dan menyampaikan value kepada konsumennya.

b. Feel Experience. Feel Experience adalah strategi dan implementasi untuk memberikan pengaruh merek kepada konsumen melalui komunikasi (iklan), produk (kemasan dan isinya), identitas produk (co-branding), lingkungan, website, orang yang menawarkan produk. Setiap perusahaan harus memiliki pemahaman yang jelas mengenai cara penciptaan perasaan melalui pengalaman konsumsi yang dapat menggerakkan imajinasi konsumen yang diharapkan dapat membuat keputusan untuk membeli. Feel Experience timbul sebagai hasil kontak dan interaksi yang berkembang sepanjang waktu, di mana dapat dilakukan melalui perasaan dan emosi yang ditimbulkan. Selain itu juga dapat ditampilkan melalui ide dan kesenangan serta reputasi akan pelayanan konsumen. Tujuan dari Feel Experience adalah untuk menggerakkan stimulus emosional (events, agents, objects) sebagai bagian dari feel strategies sehingga dapat mempengaruhi emosi dan suasana hati konsumen.

c. Think. Tujuan dari think marketing adalah membawa pelanggan mampu berpikir lebih mendalam dan kreatif sehingga memberikan opini yang bagus terhadap produk dan service perusahaan.

d. Act / Physical Experience and Entitle Lifestyle. Tujuannya adalah mendorong konsumen sehingga tertarik dan berpikir secara kreatif sehingga mungkin dapat menghasilkan evaluasi kembali mengenai perusahaan dan merek tersebut.

e. Relate / Social Identity Experience.Experience merupakan gabungan dari keempat aspek Experiential Marketing yaitu sense, feel, think, dan act. Pada umumnya Relate Experience menunjukkan hubungan dengan orang lain, kelompok lain (misalnya negara, masyarakat, budaya). Tujuan dari Relate Experience adalah menghubungkan konsumen tersebut dengan budaya dan lingkungan sosial yang dicerminkan oleh merek suatu produk.

\section{Communication}

Dalam kegiatan bisnis, komunikasi pemasaran sangatlah penting, karena untuk mempertahankan pelanggan lama dan menarik pelanggan baru perusahaan harus melakukan komunikasi yang sesuai dengan karakter konsumen sasarannya. Komunikasi adalah suatu transaksi, proses simbolik yang menghendaki orang-orang mengatur lingkungannya dengan cara membangun hubungan antar sesama, melalui pertukaran informasi, untuk menguatkan sikap dan tingkah laku orang lain, serta berusaha mengubah sikap dan tingkah laku (Sasanti, 2013). Komunikasi merupakan kondisi yang harus ada untuk terciptasebuah relasi.Dengan komunikasi, usaha-usaha yang diarahkanuntuk membangun relasi yang dilakukan setiap perusahaan supaya dapat dipahami oleh pelanggan.(Mares, 2014).

\section{Conflict Handling}

Masalah merupakan hal yang paling dihindari seorang pelanggan apabila ingin menggunakan produk atau layanan suatu perusahaan. Pihak perusahaan harus 
bias mencegah terjadinya kesalah pahaman yang bisa menimbulkan konflik terhadap pelanggannya. Hubungan antara penanganan masalah dengan loyalitas pelanggan adalah pada saat terjadinya suatu masalah pada perusahaan, pihak perusahaan langsung dapat dengan sigap menyelesaikannya sehingga tidak sampai berlarut-larut.Kemampuan conflict handling mengacu pada kemampuan perusahaan untuk mencegah atau meminimalkan dampak dari hal-hal yang potensial dapat menimbulkan konflik dan kemampuan menyelesaikan konflik nyata yang terjadi.

Dwyer et.al (indobisi 2007 : 100) Conflict Handling didefinisikan sebagai kemampuan perusahaan untuk mencegah potensi sebuah konflik, menyelesaikan konflik secara nyata sebelum mereka menjadi masalah dan mendiskusikan solusinya secara terbuka ketika ada masalah timbul. Sivesan (2012) menyatakan bahwa jika suatu perusahaan dapat dipercaya, berkomunikasi untuk layanan, dapat diandalkan, efisien dalam berkomunikasi dengan pelanggan dan mampu menangani konflik dengan baik maka konsumen akan cenderung untuk setia terhadap produk. Sivestan juga menyarankan bila perusahaan harus menjaga hubungan baik dengan para pelanggannya untuk mendapatkan kesetiaan mereka.

\section{Customer Retention}

Menurut Singh dan Khan (2012) customer retention adalah aktivitas organisasi penjualan dalam melakukan upaya untuk mengurangi customer yang gagal dipertahankan. Retensi pelanggan dimulai sejak perusahaan pertama kali melakukan kontak dengan pelanggan hingga perusahaan bisa menjalin hubungan jangka panjang dengan pelanggan [2]. Menurut Schiffman dan Wisenblit (2015) customer retention berhubungan dengan mengubah transaksi pelanggan individual menjadi hubungan pelanggan jangka panjang dengan membuat pelanggan tersebut tetap pada satu perusahaan dari pada berpindah perusahaan.

\section{Pengembangan Hipotesis}

Customer experience menjadi bagian penting dalam strategi relationship marketing karena customer experience adalah tahap utama untuk merebut hati pelanggan. Penelitian mengenai pengaruh langsung customer experience terhadap customer retention masih sangat sedikit referensinya. Namun pengaruh customer experience terhadap variabel lain yang pada akhirnya menciptakan customer retention dapat diuraikan sebagai berikut: Penelitian Hatane dan Diah (2013) dengan judul Pengaruh Customer Experience Quality terhadap Customer Satisfaction dan Customer Loyality di Kafe Excelso Tunjungan Plasa Surabaya :
Perspektif B2C, berdasarkan penelian tersebut Customer Experience Quality Berpengaruhterhadap Customer Satisfaction dan Customer Loyality. Berdasarkan Penjelasan tersebut, maka hipotesis yang diajukan adalah:

H1 : Diduga Customer Experience berpengaruh Terhadap Customer Retention.

Komunikasi dalam bisnis menjadi salah satu faktor penting dalam keberhasilan sebuah bisnis.Dengan komunikasi yang baik, pembisnis bisa menjual produk atau jasa yang dimiliki menjadi lebih baik dan juga bisa menghindari terjadinya kesalah pahaman untuk kedua belah pihak.Dalam kegiatan bisnisnya seperti pemasaran pastinya membutuhkan komunikasi yang baik terutama kepada konsumen agar produk atau jasa yang dimiliki dapat diterima sepenuhnya. Penelitian Mares (2014) Pengaruh relationship marketing terhadap customer retention orientation nasabah bank syariah di Kebumen, Relationship marketing, Belonging, Communication, Customization, Defferentiation, Personalization, Rewarding, Seccurity and Covenience.Communication berpengaruh terhadap customer retention orientation.

Berdasarkan penjelasan tersebut, maka hipotesis yang diajukan adalah:

\section{H2 : Diduga Communication berpengaruh terhadap Customer Retention}

Penelitian Lita, Samsir (2015) dengan judul Analisis relationship marketingterhadap customer satisfication dan customer retention pada nasabah Bank Muamalatcabang Bangkinang Kabupaten Kampar.Variabel dalam penelitian kepercayaan, komitmen, komunikasi, penanganan konflik. Hasil penelitian menunjukan penanganan konflik berpengaruh terhadap Customer Satification dan Customer Retention . Berdasarkan penjelasan tersebut, maka hipotesis yang diajukan adalah:

\section{H3 : Diduga Conflic Handling berpengaruh terhadap Customer Retention.}

Penelitian Yogi (2017) Pengaruh dimensi Relationship Marketing terhadap Customer Retentionpada Tiwana Musik Studio, variabel dalam penelitian ini meliputi kepercayaan, komitmen, komunikasi dan penanganan konflik. Hasil penelitian menunjukan secara simultan dimensi relationship marketing yaitu kepercayaan, komitmen, komunikasi dan penanganan keluhan memiliki pengaruh signifikan terhadap dimensi customer retention. Berdasarkan penjelasan tersebut, maka hipotesis yang diajukan adalah:

H4 : Diduga Relationship Marketing berpengaruh terhadap Customer Retention. 


\section{METODE PENELITIAN}

Populasi dalam penelitian ini adalah semua pelanggan pengguna jasa sewa Studio Musik 58 Surakarta. Teknik pengambilan sampel dalam penelitian ini menggunakan teknik purposive sampling yaitu menentukan pengambilan sampel dengan cara menetapkan ciri-ciri khusus yang sesuai dengan tujuan penelitian dengan serta menggunakan teknik convenience sampling yaitu pengambilan sampel didasarkan pada ketersediaan elemen dan kemudahan untuk mendapatkannya. Dalam menentukan jumlah sampel, penelitian ini menggunakan teori menurut Malhotra (2010) dimana dijelaskan jika populasi tidak diketahui, maka sampel dapat diambil dengan menghitung jumlah pernyataan (n) dikali 5 keseluruhan pernyataan dalam penelitian ini berjumlah 16 pernyataan sehingga jika dikali 5, maka sampel yang diperoleh sebanyak 80 sampel. Sampel dalam penelitian ini adalah pelanggan pengguna jasa sewa Studio Musik 58 Surakarta yang memiliki kriteria tertentu yaitu:

a) responden yang menggunakan jasa di Studio Musik 58 lebih dari dua kali.

b) responden yang mudah ditemui dan memiliki waktu luang untuk mengisi kuesioner.

\section{HASIL DAN PEMBAHASAN}

Hasil uji t, customer experience diperoleh $t_{\text {hitung }}$ sebesar 1.484 dan signifikansi sebesar 0.142 . Nilai $t_{\text {hi- }}$ tung lebih kecil dari tabel dan signifikansi customer experience lebih besar dari 0,05 dan nilai koefisien regresi 0.197 maka dapat disimpulkan bahwa H0 diterimadan $\mathrm{H} 1$ ditolak. Hal ini berarti bahwa customer experience secara parsial tidak secara langsung berpengaruh terhadap customer retention namun membutuhkan faktor pendukung yang lain seperti kepercayaan, kepuasan, komitmen, sehingga customer experience dapat meningkat dan pada akhirnya membentuk customer retention.

Hasil uji t, communication diperoleh thitung sebesar 1.773 dan signifikansi sebesar 0,045 . Nilai thitung communication lebih besar dari tabel dan signifikansi communication lebih kecil dari 0,05, maka dapat disimpulkan bahwa $\mathrm{H} 0$ ditolak dan $\mathrm{H} 2$ diterima. Hal ini berarti communication yang baik mempengaruhi tingkat customer retention.

Hasil uji $\mathrm{t}$ conflict handling diperoleh $\mathrm{t}_{\text {hitung }}$ sebesar 6.421 dan signifikansi sebesar 0,000. Nilai $t_{\text {hi- }}$ tungconflict handling lebih kecil dari $\mathrm{t}_{\text {tabel }}$ dan signifikansi conflict handling lebih besar dari 0,05, maka dapat disimpulkan bahwa $\mathrm{H} 0$ ditolak dan $\mathrm{H} 3$ diterima.
Hal ini berarti jika pemilik studio musik dapat menangani konflik yang terjadi secara baik akan berdampak pada peningkatan customer retention.

Berdasarkan hasil uji $\mathrm{F}$ di atas diperoleh $\mathrm{F}_{\text {hitung }}$ sebesar 27.691 ( $\left.F_{\text {hitung }} 27.691>F_{\text {tabel }} 2.72\right)$. Nilai probabilitas lebih kecil dari 0,05 (sig $F_{\text {hitung }} 0,000<0,05$ ), maka dapat disimpulkan $\mathrm{H} 0$ ditolak yang berarti bahwa customer experience, communication, conflict handling secara bersama-sama berpengaruh terhadap customer retention sebesar 27.691.

Berdasarkan hasil uji Adjusted R. Square diperoleh nilai sebesar 0,503 . Hal ini menunjukkan bahwa hanya $50,3 \%$ variasi dari customer retention dapat dijelaskan oleh variabelcustomer experience, communication, conflict handling. Sedangkan sisanya sebesar 49,7\% dijelaskan oleh variabel lain yang tidak masuk dalam model penelitian.

\section{KESIMPULAN DAN SARAN}

Variabel customer experience memiliki t hitung sebesar 1.773 dan t tabel 1.664 secara parsial tidak berpengaruh secara langsung terhadap customer retention karena variabel customer experience membutuhkan faktor pendukung yang lain seperti kepercayaan, kepuasan, komitmen, agar customer experience dapat meningkat, sehingga pada akhirnya konsumen menjadi loyal dan terjadi customer retention. Variabel communication berpengaruh signifikan dan positif dengan nilai t hitung 1,773dan t tabel 1.664 terhadap cutomer retention. Hal ini berarti communication yang semakin baik akan berdampak terhadap keinginan pelanggan untuk terus menggunakan jasa sewa studio dan enggan untuk berpindah ke studio lain. Hal ini dapat meningkatkan customer retention. Variabel conflict handling berpengaruh signifikan dengan thitung sebesar 6,421 dan t tabel 1.664 positif terhadap customer retention. Hal ini berarti conflict handling yang baik akan meningkatkan customer retention, karena pelanggan menjadi nyaman dan tidak kuatir apabila terjadi masalah atau konflik akan teratasi dengan sangat baik. Variabel customer experience, communication, conflict handling berpengaruh secara simultan sebesar 27,961 terhadap customer retention.

\section{Keterbatasan Penelitian}

Penelitian ini merupakan penelitian cross sectional yaitu data yang digunakan hanya sesaat atau data yang diperoleh adalah saat ini juga dan hanya berlaku untuk obyek penelitian ini saja. Variabel yang digunakan dalam penelitian ini adalah Customer Experience, Communication, Conflict Handling, oleh karena itu untuk mengoptimalkan hasil penelitian ini harus ada penelitian selanjutnya mengenai variabel-variabel lain 
yang dapat mempengaruhi Customer Retention. Adapun variabel lain yang dapat dijadikan referensi bagi peneliti selanjutnya diantara lain kepercayaan, komitmen, kepuasan dan lain sebagainya.

\section{Saran}

Berdasarkan kesimpulan di atas variabel customer experience tidak berpengaruh secara parsial terhadap customer retentionoleh sebab itu disarankan kepada pemilik Studio Musik 58 Surakarta agar lebih lagi memberi pengalaman positif kepada pelanggan agar pelangganpun tetap kembali untuk berlatih di Studio Musik 58 Surakarta. Pengalaman yang baik akan membuat konsumen tetap setia dan menjadi loyal sehingga pada akhirnya enggan untuk berpindah kestudio lain. Contoh tentang memberi pengalaman yangpositif adalah pemilik studio musik 58 selalu menyediakan alat musik yang ready to use(siap digunakan), ruangan bersih sehingga latihan yang nyaman, AC tidak rusak, ada fasilitas WIFI, dan Monitor dalam studio terkoneksi dengan WIFI sehingga memudahkan dalam pencarian lirik dan chord.

Peneliti menyarankan untuk meningkatkan ketrampilan komunikasi bagi para staff yang bertugas dengan carakomunikasi yang baik dan jelas. Konsumen yang yang loyal akan enggan berpindah studio (terjadi retensi) dan mau merefrensikan kepada calon konsumen baru. Contoh tentang komunikasi adalah pemilik studio memberi sapaan yang ramah ketika pengunjung datang untuk menyewa studio musik, pemilik studio memberikan penjelasan aturan pemakaian sewa studio dengan baik dan jelas dan mencatat jadwal pemesanan sewa tercatat dengan rapi.

Peneliti menyarankan karena variabel conflict handling berpengaruh signifikan positif terhadap customer retention oleh sebab itu disarankan kepada pemilik Studio Musik 58 Surakarta, mepertahankan cara penanganan konflik yang baik kepada konsumen studio musik 58 Surakarta. Contoh penanganan konflik yang baik ketika terjadi kemunduran jam, pemilik studio mau menjelaskan dengan baik dengan alasan yang sejujurnya kepada pelanggan sehingga pelanggan mengerti kenapa kemunduran jam bisa terjadi, dan memberikan kompensasi dengan cara penambahan waktu (15 - 20 menit) dengan tujuan untuk konsumen atau pelanggan tidak kecewa dan cukup terakomodasi dengan layanan tambahan waktu.

\section{REFERENSI}

[1] R. Setiawan and D. A. Kurniawan, "Analisis Tourist Experience Terhadap Revisit Intention pada Objek Wisata Air Panas Se Kabupaten Garut," Bus. Innov. Entrep. J., vol. 1, no. 3, pp.
175-180, 2019, doi: 10.35899/biej.v1i3.70.

[2] A. Solihat, H. F. Tampubolon, R. Rahmayani, and A. Trijumansyah, "Analisis Kepercayaan dan Kualitas Situs pada Minat Beli Produk ECommerce Bukalapak," Bus. Innov. Entrep. J., vol. 1, no. 2, pp. 72-81, 2019, doi: 10.35899/biej.v1i2.55.

[3] Chen, S.-C \& Lin, C. -P. (2014).The Impact Of Customer Experience And Perceived Value On Sustainable Social Relationship In Blog: An Empirical Study. Technological Forecasting \& Social Change xxx (2014), PP.1 -11.

[4] Hatane Dan Diah, 2013, Judul Pengaruh Customer Experience Quality Terhadap Customer Satisfaction Dan Customer Loyaliti Di Kafe Excelso Tunjungan Plasa Surabaya : Perspektif B2C, Jurnal Manajemen Pemasaran Petra Vol.1, No.1, (2013) 1-15.

[5] Janie, Dyah Nirmala arum, 2012, statistic Deskriptif \& Regresi linier Berganda Dengan SPSS, http://repository.usm.ac.id/files/bookusm/B208/201705190 22209-statistik-Deskriptif-\&-Regresi-LinierBerganda-Dengan-SPSS-pdf., Diambil Pada Hari Kamis, 24 oktober 2019 pukul 23.00 WIB

[6] Lita dan samsir, 2015, Analisis relationship marketingterhadap customer satisfication dan customer retention pada nasabah Bank Muamalat cabang Bangkinang Kabupaten Kampar, Universitas Riau.

[7] Malhotra, 2010, marketing research : an Applied orientation sixth edition person.

[8] Mares., 2014, Pengaruh Relationship Marketing Terhadap Customer Retention Orientation Nasabah Bank Syariah Di Kebumen, Universitas Muhamadiyah Purworejo.

[9] Nikmah, 2017., Hubungan Relationship Marketing, Customer Satisfaction dan Customer Loyalty., UNiversitas TrunojoyoMadura.

[10] Nurinda, Asep, Et Al, 2019, Analisis Nilai Pelanggan Dan Pengalaman Pelanggan Terhadap Kepercayaan Pelanggan Wisata Kuliner Selamat Toserba Sukabumi, Universitas $\mathrm{Mu}-$ hamadiyah Sukabumi.

[11] Pranoto, Subagio, 2015, Analisa Pengaruh Customer Experience TerhadapCustomer Satisfaction Pada Konsumen di Rosetta's Café dan 
Resto Surabaya, Universitas Kristen Petra, Surabaya.

[12] Salim, Chatrine dan Andreani., 2013., Pengaruh Customer Experience dan Kepercayaan Terhadap Kepuasan Konsumen Di TX Travel Klampis, Universitas Kristen Petra, Surabaya.

[13] Sangadji, M. Etta dan Sophia., 2010., Metode Penelitian Pendekatan Praktis Dalam Penelitian., ANDI., Bamdung.

[14] Saputra Dan Ariningsih, 2014, Masa Depan Penerapan Strategi Relationship Marketing Pada Industry Jasa Perbankan, Segmen Jurnal Manajemen Dan Bisnis, Volume 10 No. 1.

[15] Sasanti., 2013., Pengaruh Dimensi Relationship Marketing Terhadap Loyalitas Pelanggan (Studi Kasus Pada Katering Prima Semarang), Universitas Negeri Semarang.

[16] Schiffman dan Wisenblit, Pengertian Customer Retention.http://bbs.binus.ac.id/internationalmarketing/2018/08/customer-retentionSenin, 2 September 2019, 16.00 WIB

[17] Singh Dan Khan, Pengertian Customer Retention. http://bbs.binus.ac.id/international-marketing/2018/08/customer-retentionSenin, 2 September 2019, $16.00 \mathrm{WIB}$

[18] Sivesan, 2012, Impact Of Relationship Marketing On Customer Loyalyty On Banking Sector, Journal Of South Academic Research, Volume 2, Isuue3, Pp. 179-191

[19] Sugiyono, 2015, Metode Penelitian Kombinasi (mix methods). Bandung: Alfabeta

[20] Sugiyono,2010. Metode Penelitian Kuantitatif, Kualitatif, dan R\&D. Bandung: Alfabeta.
[21] Suliyanto, 2011, "Ekonometrika Terapan: Teori Dan Aplikasi Dengan Spss". Edisi 1. Yogyakarta: ANDI Yogyakarta.

[22] Syaqira, F. (2014).Managing Customer Retention Of Hotel Industry In Malaysia Social And Behavioral Sciences.

[23] Tiara, 2015, Pengaruh Relationship Marketing Terhadap Customer Retention Pada Wardah Beauty House Yogyakarta, Universitas Islam Negeri Sunan Kalijaga Yogyakarta.

[24] Tjiptono, 2015. Strategi Pemasaran Edisi: 4: Andi

[25] Velnampy Dan Sivesan, 2012, Customer Relationship Marketing Andcustomer Satisfaction: A Study On Mobile Service Providing Companies In Srilangka.

[26] Widodo,2017, METODE PENELITIAN Populer dan Praktis. Jakarta: Rajawali Pers.

[27] Yoana, 2013, Analisa Pengaruh Customer Value dan customer Experience terhadap Customer Satisfaction di De Kasteel Resto Surabaya, Universitas Kristen Petra Surabaya.

[28] Yogi, 2017, Pengaruh dimensiRelationship Marketing terhadap Customer Retentionpada Tiwana Musik Studio, Universitas Lampung Bandar Lampung.

[29] Zangmo et al, Pengertian Customer Retention. http://bbs.binus.ac.id/international-marketing/2018/08/customer-retentionSenin, 2 September 2019, $16.00 \mathrm{WIB}$ 